\title{
Correction to: A Systematic Review of Methodological Variation in Healthcare Provider Perspective Tuberculosis Costing Papers Conducted in Low- and Middle-Income Settings, Using An Intervention-Standardised Unit Cost Typology
}

\author{
Lucy Cunnama ${ }^{1}$ - Gabriela B. Gomez ${ }^{2} \cdot$ Mariana Siapka $^{2} \cdot$ Ben Herzel $^{3}$ - Jeremy Hill ${ }^{2}$. Angela Kairu ${ }^{1}$ - Carol Levin ${ }^{4}$. \\ Dickson Okello ${ }^{1}$. Willyanne DeCormier Plosky ${ }^{5} \cdot$ Inés Garcia Baena ${ }^{6} \cdot$ Sedona Sweeney $^{2} \cdot$ Anna Vassall $^{2}$. \\ Edina Sinanovic ${ }^{1}$
}

Published online: 27 May 2020

(C) The Author(s) 2020

\section{Correction to: PharmacoEconomics (2020) https://doi.org/10.1007/s40273-020-00910-w}

In the original version of this article, Fig. 3 was published in an incorrect format. The correct figure is published with this correction.

Open Access This article is licensed under a Creative Commons Attribution 4.0 International License, which permits use, sharing, adaptation, distribution and reproduction in any medium or format, as long as you give appropriate credit to the original author(s) and the source, provide a link to the Creative Commons licence, and indicate if changes were made. The images or other third party material in this article are included in the article's Creative Commons license, unless indicated otherwise in a credit line to the material. If material is not included in the article's Creative Commons licence and your intended use is not

The original article can be found online at https://doi.org/10.1007/ s40273-020-00910-w.

Lucy Cunnama

Lucy.Cunnama@uct.ac.za

1 Health Economics Unit, School of Public Health and Family Medicine, Faculty of Health Sciences, University of Cape Town, Anzio Road, Cape Town, South Africa

2 Department of Global Health and Development, Faculty of Public Health and Policy, London School of Hygiene and Tropical Medicine, London, UK

3 Institute for Health Policy Studies, University of California, San Francisco, CA, USA

4 Department of Global Health, University of Washington, Seattle, WA, USA

5 Avenir Health, Glastonbury, CT, USA

6 TB Monitoring and Evaluation (TME), Global TB Programme, The World Health Organization, Geneva, Switzerland permitted by statutory regulation or exceeds the permitted use, you will need to obtain permission directly from the copyright holder. To view a copy of this licence, visit http://creativecommons.org/licenses/by/4.0/. 


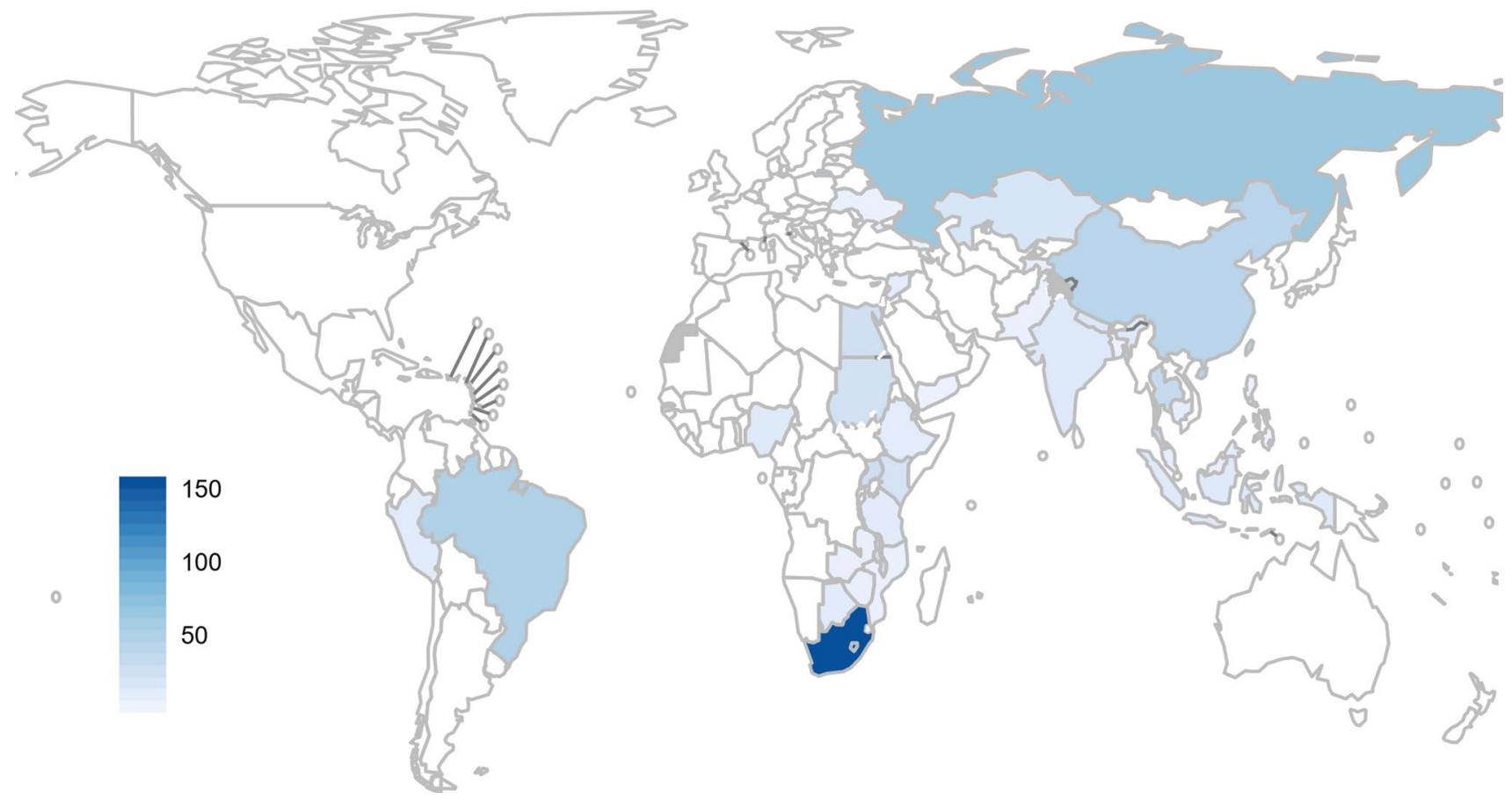

Fig. 3 Number of unit costs for TB interventions available in low- and middle-income countries 